\title{
Somatostatin in the rat periventricular nucleus: sex differences and effect of gonadal steroids
}

\author{
Harmke H. Van Vugt • Bert J. M. Van de Heijning • \\ Eline M. Van der Beek
}

Received: 22 January 2008 / Accepted: 4 April 2008 / Published online: 18 April 2008

(C) The Author(s) 2008

\begin{abstract}
In the rat, the sexual dimorphism in growth hormone release is driven by sex steroids, and is suggested to result mainly from differences in somatostatin (SOM) release patterns from the median eminence. We studied the effect of gonadal steroids on SOM peptide-containing cells in the periventricular nucleus $(\mathrm{PeVN})$ of ovariectomized (OVX) female rats, and compared these data with data from intact male rats. Adult female rats were treated with estradiol $\left(\mathrm{E}_{2}\right)$ and/or progesterone $(\mathrm{P}), 3$ months (long-term) or 2 weeks (short-term) after ovariectomy (OVX). Perfusionfixed brains were sliced and stained, and the number of SOM-immunoreactive (-ir) cells and total SOM-ir area (in $\mu \mathrm{m}^{2}$ ) were determined using computer assisted analysis. SOM-ir cells in the PeVN showed a very characteristic rostro-caudal distribution and localization in relation to the third ventricle. Both the number of SOM-ir cells and total SOM-ir area in the PeVN were higher in male compared to OVX female rats. Neither the number of SOM-ir cells, nor the total SOM-ir area in the PeVN was affected by $\mathrm{E}_{2}$ or $\mathrm{P}$ treatment alone. Treatment with both gonadal steroids,
\end{abstract}

H. H. Van Vugt - B. J. M. Van de Heijning - E. M. Van der Beek Human and Animal Physiology Group, Animal Sciences Group, Wageningen University, 6709 PG Wageningen, The Netherlands

Present Address:

H. H. Van Vugt

Novartis Institutes for BioMedical Research, 4002 Basel, Switzerland

e-mail: harmkevanvugt@ hotmail.com

Present Address:

B. J. M. Van de Heijning · E. M. Van der Beek ( $\square)$

Danone Research Centre for Specialized Nutrition,

PO Box 7500, 6700 CA Wageningen, The Netherlands

e-mail: eline.vanderbeek@danone.com however, did increase total SOM-immunoreactivity. This study is the first to describe SOM cell distribution within the rat $\mathrm{PeVN}$ in great detail. A clear sex difference exists in SOM peptide content in the rat $\mathrm{PeVN}$. In addition, $\mathrm{E}_{2}$ and $\mathrm{P}$ may act synergistically to affect SOM cells in the female PeVN, suggesting that both gonadal steroids may be involved in the generation of the typical feminine SOM release pattern.

Keywords Somatostatin peptide - Gonadal steroids · Growth hormone $\cdot$ Hypothalamus $\cdot$ Estrogen sensitivity Sex difference

\section{Introduction}

In the rat, growth hormone $(\mathrm{GH})$ release patterns are sexually dimorphic (Clark et al. 1987; Eden 1979; Gatford et al. 1998). In males, GH secretion is characterized by regular high amplitude pulses occurring at approximately 3-h intervals, and low baseline levels. Females exhibit irregular low amplitude GH levels and higher baseline levels than males (Clark et al. 1987; Eden 1979; Gatford et al. 1998).

Release of GH from the pituitary is mainly regulated by the interplay between the stimulating effects of GH-releasing hormone (GHRH), synthesized in cells of the arcuate nucleus of the hypothalamus (ARC), and the inhibiting effects of somatostatin (SOM), synthesized in cells of the periventricular nucleus of the hypothalamus $(\mathrm{PeVN})$ (Critchlow et al. 1981; Gillies 1997; Katakami et al. 1988; Praputpittaya et al. 1987; Tannenbaum and Ling 1984; Tannenbaum et al. 1990; Terry and Martin 1981; Urman et al. 1985; Zeitler et al. 1991). Also ghrelin is found to stimulate GH release and ghrelin-producing cells in the hypothalamus may stimulate GHRH cells in the ARC 
(Korbonits and Grossman 2004). However, the exact role, as well as the impact of ghrelin in the hypothalamic regulation of $\mathrm{GH}$ secretion remains uncertain.

The typical masculine and feminine GH secretion patterns are most likely the direct result of differences in SOM and GHRH release patterns between the sexes. In male rats, SOM is released in regular pulses with maximal levels during a GH trough and minimal levels during a $\mathrm{GH}$ peak (Kasting et al. 1981; Plotsky and Vale 1985; Tannenbaum and Ling 1984; Tannenbaum et al. 1990, 1993; Zeitler et al. 1991). In females, SOM release is thought to be more constant, and at a level in-between the maximum and minimum levels that are observed in males (Clark and Robinson 1985; Painson and Tannenbaum 1991), although relatively small and irregular SOM peaks have also been reported (Estupina et al. 1996). GHRH release from the ME on the other hand, appears to be pulsatile in both sexes, albeit regular in male rats, with peak levels occurring during the SOM troughs, and irregular in females (Clark and Robinson 1985; Jansson et al. 1985; Painson and Tannenbaum 1991; Plotsky and Vale 1985; Tannenbaum and Ling 1984; Tannenbaum et al. 1990; Zeitler et al. 1991). Thus, with respect to the bimodal hypothalamic regulation of $\mathrm{GH}$ release, differences in SOM release are most pronounced between the sexes. Therefore, the sexual dimorphism in $\mathrm{GH}$ release has been suggested to result mainly from differences in SOM release patterns from the median eminence (ME) (Gillies 1997; Muller et al. 1999; Tannenbaum et al. 1990).

As GH release patterns are highly dependent on the gonadal steroidal milieu (Jansson et al. 1984; Jansson and Frohman 1987a; b), the synthesis and release of SOM may also be affected by gonadal steroids. Indeed, castration of male rats decreases both hypothalamic SOM mRNA levels and SOM peptide content, which can be restored by treatment with testosterone (Bethea et al. 1992; Chowen-Breed et al. 1989; Murray et al. 1999; Werner et al. 1988; Zorilla et al. 1991). In female rats, estradiol ( $\left.E_{2}\right)$ affects both hypothalamic SOM mRNA and peptide levels, although conflicting results have been reported: Neither ovariectomy (Murray et al. 1999), nor $\mathrm{E}_{2}$ treatment of ovariectomized (OVX) rats (Estupina et al. 1996) affects the total hypothalamic SOM peptide content. In contrast, SOM mRNA levels in the PeVN also decrease following OVX, but this reduction can be reversed by treatment with $\mathrm{E}_{2}$ (Bethea et al. 1992; Werner et al. 1988; Zorilla et al. 1990). In addition, it is reported that in the cycling female rat hypothalamic SOM content and SOM release from the ME fluctuate concurrently with plasma $\mathrm{E}_{2}$ levels during the estrous cycle (Estupina et al. 1996; Freeman 1994; Knuth et al. 1983; Zorilla et al. 1991). This suggests that $E_{2}$ may indeed affect hypothalamic SOM synthesis and release. The precise role of $E_{2}$ in the regulation of hypothalamic SOM system activity in the female rat remains to be established.
Also progesterone $(\mathrm{P})$, which has a direct feedback action at the brain level to control the female reproductive cycle (Freeman 1994), may be involved in the regulation of the typical feminine SOM release pattern. To date, the role of progesterone in the hypothalamic regulation of $\mathrm{GH}$ release has not been studied at all.

In the present study, we first compared the distribution of SOM cells within the PeVN between adult OVX female and male rats in detail. In addition, we examined the effects of gonadal steroids on the number of SOM cells and on SOM peptide content in the PeVN of female rats.

\section{Methods}

\section{Animals}

A total of 46 Wistar rats (8 adult males and 38 adult females) (Harlan, Horst, The Netherlands) were pairhoused in a room with controlled lighting (12L:12D, lights on at $04.00 \mathrm{~h})$, temperature $\left(23^{\circ} \mathrm{C}\right)$, and humidity $(70 \%)$. Standard pelleted food and tap water were available ad libitum. A dim red light remained on at all times, including the dark period. Males were 4 months old and females were 11-12 weeks (group I, $n=32$ ) or 16 weeks (group II, $n=6$ ) old on arrival. All experiments were carried out in accordance with the "Principles of laboratory animal care" of the NIH and the Wageningen University Animal Ethics Committee approved all experiments.

\section{Experimental design}

All female rats underwent bilateral ovariectomy $(\mathrm{OVX})$ at 12 weeks of age (group I) or at the age of 18 weeks (group II) under gas anesthesia with a mixture of Isoflurane (Isoflo; Abbott Laboratories Ltd, England) and oxygen (3:1 ratio). Three months $(3 \mathrm{mo}$ ) after OVX, the females of group I ("long-term") received a subcutaneous (s.c.) injection with estradiol benzoate (EB; $12.5 \mu \mathrm{g} / 0.1 \mathrm{ml}$ cottonseed oil; $n=16)$ or with $0.1 \mathrm{ml}$ cottonseed oil only $(n=16)$ between 08:30 and 09:00 h on two consecutive days (treatment day 1 and 2). On day 3, the rats received an s.c. injection with either progesterone (P; $0.25 \mathrm{mg} / 0.1 \mathrm{ml}$ cottonseed oil) ("OVX $+\mathrm{P} ", n=8$ and "OVX $+\mathrm{E}_{2}+\mathrm{P} ", n=8$ ) or with $0.1 \mathrm{ml}$ cottonseed oil only ("OVX", $n=8$ and "OVX $+\mathrm{E}_{2}$ ", $n=8)$ at 11:00 h.

As results obtained from previous studies in our lab suggested that the time period of steroid deprivation following OVX may change the sensitivity of SOM cells to $\mathrm{E}_{2}$ feedback (unpublished data), an additional group of OVX females was included (group II, "short-term") to compare the effects of EB treatment between short-term and longterm OVX animals on hypothalamic SOM peptide levels. 
Rats in group II ("short-term") received the two s.c. injections with EB (treatment day 1 and 2) and an s.c. injection with oil (treatment day 3), 2 weeks after OVX.

On treatment day 3 , all female and male rats were perfused just prior to dark onset, i.e. between 15:30 and 16:00 h. Prior to perfusion, animals were given an overdose of $\mathrm{Nembutal}^{\circledR}$ anesthesia (CEVA sante animale B.V., Maassluis, The Netherlands; $1.5 \mathrm{ml} / \mathrm{kg}$ body weight; i.p.). Rats were perfused transcardially with $200 \mathrm{ml}$ (females) or $300 \mathrm{ml}$ (males) saline followed by $300 \mathrm{ml}$ (females) or $400 \mathrm{ml}$ (males) Somogyi fixative (2\% paraformaldehyde in $0.1 \mathrm{M}$ phosphate buffer $\mathrm{pH} 7.4$ with $0.1 \%$ glutaraldehyde and $0.2 \%$ saturated picric acid) (Somogyi and Takagi 1982). Brains were removed from the skull immediately after perfusion and post-fixed in the same fixative for $25 \mathrm{~h}$ at $4^{\circ} \mathrm{C}$. Tissue blocks containing the hypothalamus were sliced into coronal sections of $40 \mu \mathrm{m}$ using a Vibratome (Vibratome Company, St Louis, USA; series 1500), distributed into three series of alternating sections and stored in $0.1 \mathrm{M}$ Tris buffer containing $0.9 \% \mathrm{NaCl}$ (TBS, $\mathrm{pH} 7.4$ ) at $4^{\circ} \mathrm{C}$ until immunocytochemistry.

\section{Immunocytochemistry}

One series of sections (one-third of the total hypothalamus) of each animal was stained for SOM peptide using freefloating immunocytochemistry techniques (Van der Beek et al. 1994). Sections were pretreated with $3 \% \quad \mathrm{H}_{2} \mathrm{O}_{2}$ (Merck, Darmstadt, Germany) in TBS for $30 \mathrm{~min}$, followed by extensive washing with TBS. Subsequently, sections were incubated with the primary polyclonal rabbit antibody raised against SOM peptide (Somaar 080289, NIH, Amsterdam, The Netherlands; final dilution 1:30,000) (Buijs et al. 1989), diluted in supermix (TBS containing $0.5 \%$ Triton-X-100 and $0.25 \%$ gelatin) for one night at $4{ }^{\circ} \mathrm{C}$. This was followed by incubation with biotinylated goat anti-rabbit Immunoglobulin G (GaR-bio; Vector Laboratories; Burlingame, CA; USA, 1:500 in supermix) for $1.5 \mathrm{~h}$ at room temperature, and Avidin-Biotin Complex-elite (ABC; Vector Laboratories; final dilution 1:1,500 in supermix) for $1.5 \mathrm{~h}$ at room temperature. Between incubation steps, sections were thoroughly washed with TBS. Immunoreactivity for SOM was visualized by incubation with $0.05 \% 3,3^{\prime}$ diaminobenzidine (DAB; Sigma Chemical Company, St Louis, MO, USA) in TBS containing $0.1 \%$ imidazole and $0.03 \% \mathrm{H}_{2} \mathrm{O}_{2}$ for $14.5 \mathrm{~min}$.

Stained sections were mounted on albumin-coated slides, dried, dehydrated and coverslipped in DEPEX (BDH Laboratory Supplies, Poole, England). SOM-immunoreactive (SOM-ir) neurons in the PeVN were counted using computer assisted image analysis (Scion Image Beta, version 4.02; Scion Corporation, Maryland, USA) following background correction (Bethea et al. 1992).

\section{Selection of the PeVN area}

Images of the left side of the brain containing the PeVN (standardized to 9 images per rat brain) were captured using a microscope (50x magnification) with a digital black-andwhite CCD camera (Sony, XC-77CE) connected to a computer. The nine consecutive sections ( $80 \mu \mathrm{m}$ apart) containing the PeVN were selected using several criteria, including the shape of the third ventricle and the optic chiasm as well as the staining pattern. The first section of the PeVN included for analysis was the section in which the suprachiasmatic nucleus (SCN) first appeared (Plate 22 according to Paxinos and Watson (Paxinos and Watson 1986). The last section of the PeVN included for analysis was the last section before the ventral medial nucleus (VMN), containing dense SOM fiber staining, first appeared (Plate 26 Paxinos and Watson 1986). The total PeVN, defined as described above includes all periventricular SOM cells that have been shown to project to the ME (Ishikawa et al. 1987; Merchenthaler et al. 1989). In line with previous reports (Argente et al. 1990; Epelbaum et al. 1986; Willoughby et al. 1989) and for evaluation purposes only, the total length of the PeVN was divided into three rostro-tocaudal subregions: the anterior, medial, and posterior PeVN, referring to respectively PeVN sections $1-3,4-6$ and 7-9.

For schematic camera lucida drawings of the PeVN, images were imported into Adobe Illustrator (version 8.0), a drawing program in which schematic drawings can be made by placing an empty layer over the image file. In this layer, immunoreactive neurons were marked and saved.

\section{Data analysis}

Images of the left side of the brain containing the PeVN, covering the 9 consecutive PeVN sections as described above, were captured using a microscope $(100 \times$ magnification) with a digital black-and-white CCD camera (Sony, $\mathrm{XC}-77 \mathrm{CE})$ connected to a computer. Unilateral analysis was performed since no significant differences in SOMimmunoreactivity (-ir) and cell number within the PeVN were detected between the left and right side of the hypothalamus (unpublished results). Images were analyzed using an image analysis program (Scion Image Beta, version 4.02; Scion Corporation, Maryland, USA) applying gray level threshold discrimination (Bethea et al. 1992). By capturing each image at the same gray level, i.e. the average gray level of the entire image, a background correction was made. Subsequently, the gray level was used to determine the threshold for analysis by measuring true background (i.e. the gray level in an area that contained SOM-ir fibers, but no SOM-ir cell bodies) in a representative selection of all images. The threshold was calculated based on 
the mean true background gray value $+3 x$ standard deviation, thus reducing the chance of false positive cell counts to $P<0.01$. Using this threshold, the number of SOM-ir neurons was counted automatically. A cutoff size of 5 pixels $\left(16.2 \mu \mathrm{m}^{2}\right)$ was used as a lower limit; excluding the possibility of including dendrites in the automated cell count (see Fig. 1).
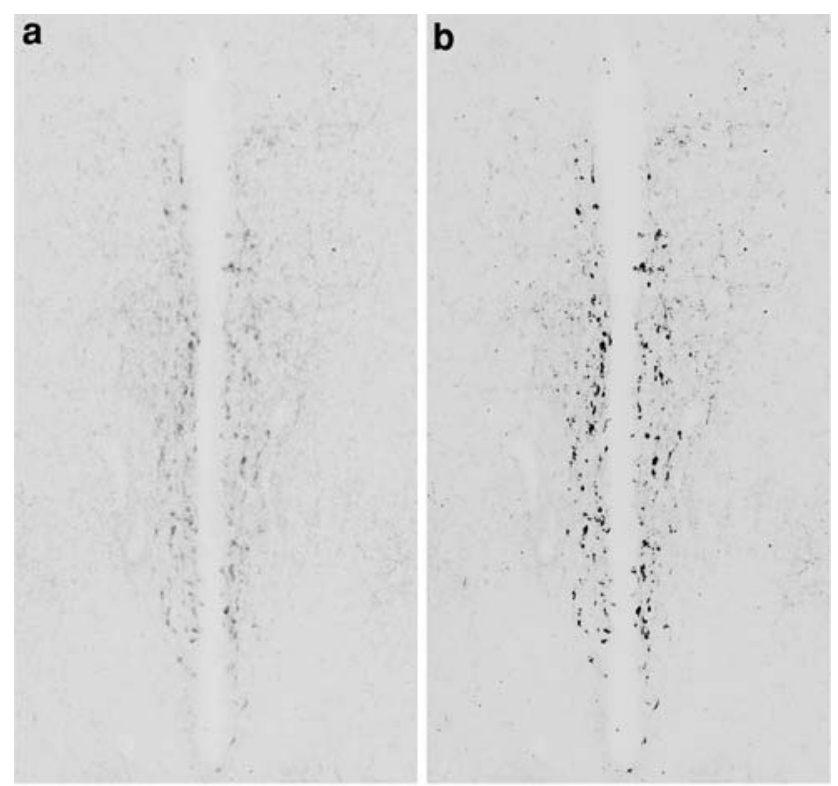

C

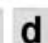

d

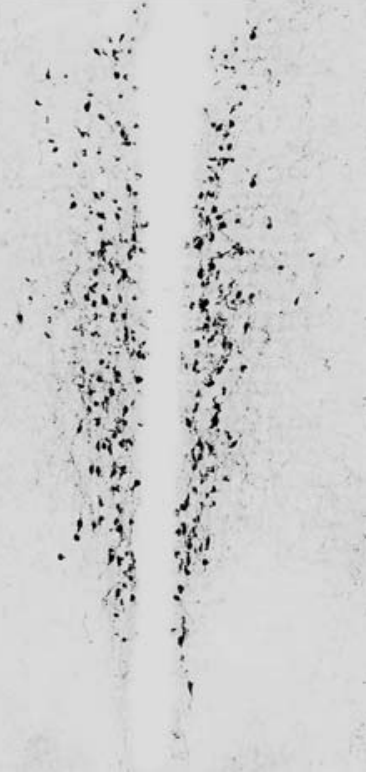

Fig. 1 Automated image analysis of SOM cells in the PeVN. Densitometric analysis of SOM-ir cells in the PeVN using a defined threshold level (see text for details). Pictures of the whole PeVN were taken from sections defined as PeVN level 5 from one representative OVX $+\mathrm{E}_{2}$ (a) and one representative male animal (c) $(\times 100$ magnification). In $\mathbf{b}$ $\left(\mathrm{OVX}+\mathrm{E}_{2}\right)$ and $\mathbf{d}$ (male) all staining intensity above the defined threshold level is shown in black (using the automated image analysis system). Only black dots larger than 5 pixels (i.e. $16.2 \mu \mathrm{m}^{2}$ ) were considered as a positively stained cell by the image analysis system (measuring results not shown)
The mean average number of neurons per section as well as the mean cumulative number of cells per animal (i.e. total SOM number of nine PeVN sections) was calculated for each group (mean \pm SEM). In addition to cell counts, we also analyzed the total area (in $\mu^{2}$ ) covered by SOMimmunoreactivity above threshold level using the same images and analysis program as described above. This measurement provides a reliable tool to estimate the amount of SOM peptide present in the PeVN and is independent of cell size. In general, SOM cell number and SOM-ir measurements showed a significant and very high correlation within individual animals in all groups, both males and females (data not shown).

For statistical analysis, the total number of SOM-ir cells and total SOM-ir area, i.e. the sum of nine PeVN sections ("total PeVN"), were used. In addition to this, we analyzed the number of SOM-ir cells and SOM-ir area in the anterior, medial, and caudal part of the PeVN.

Data were analyzed using the SPSS statistical analysis system (SPSS, Chicago, IL, USA). Oneway ANOVAs were used to compare both the total number of SOM-ir cells and total SOM-ir area (total PeVN and PeVN sub regions) between the male group and all female groups, and between the different gonadal steroid treatments within OVX female groups. In addition, separate Bonferroni Tests were used for post-hoc testing to compare both the number of SOM-ir cells and SOM-ir area between different gonadal steroid treatments in OVX females. To compare the effect of short-term versus long-term ovariectomy on the number of SOM-ir cells and SOM-ir area (total PeVN and PeVN sub regions), separate $T$-tests were used. Differences were considered to be significant when $P<0.05$.

\section{Results}

Rostro-caudal distribution of SOM cells within the PeVN

SOM immunoreactivity was found in cell bodies and fibers dispersed within a small zone just alongside the third ventricle in both males and females, as previously described (Ishikawa et al. 1987). Most cells within this region were darkly stained large neurons, frequently showing more than one immunoreactive dendrite extending from the cell body. Immunoreactivity within the cell was localized in the cytoplasm, resulting in a lighter stained central zone in the cell soma representing the unstained nuclear region (Fig. 2)

The rostral-caudal distribution of SOM-immunoreactive (-ir) cells within the PeVN was comparable between the sexes and showed a characteristic localization and distribution pattern in relation to the third ventricle (Figs. 3, 4). In 
Fig. 2 SOM cells in the PeVN. Photographs showing SOM immunoreactivity in the PeVN of a representative male (a) and $\mathrm{OVX}+\mathrm{E}_{2}$ female rat (b). Pictures of the right side of the ventricle were taken at a high magnification $(\times 400)$ from sections defined as PeVN level 5
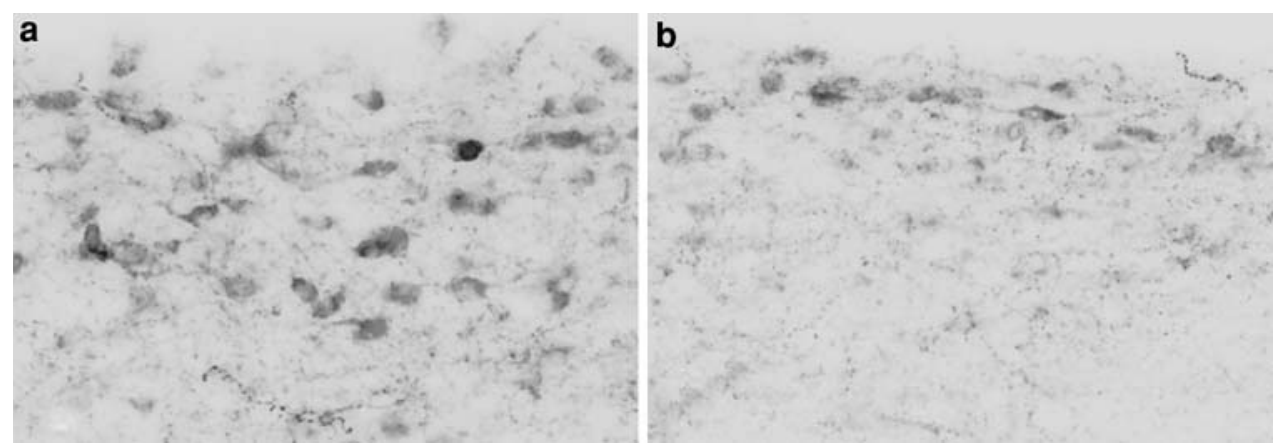

the anterior part of the PeVN (sections 1-3) a small, dense population of SOM-ir cells was located just above the suprachiasmatic nucleus ( $\mathrm{SCN}$ ), directly lined along the ventricle wall. Moving more caudally towards the medial part of the PeVN (sections 4-6), a dense population of SOM-ir cells covered the whole length of the third ventricle side area, with maximum numbers of SOM-ir cells at the midlevel (from ventral to dorsal) of the ventricle. Finally, in the posterior part of the PeVN (sections 7-9) small populations of SOM-ir cells were located for the most part along the mid- and dorsal part of the ventricle wall (Fig. 3).

The total SOM-ir cell number was consistently higher in male compared to ovariectomized (OVX) female rats throughout the PeVN (Fig. 4). The rostro-caudal distribution within the PeVN appeared to be slightly different between the sexes, i.e. maximal SOM-ir cell numbers were found in section 7 in males, but consistently in section 6 in the OVX females, irrespective of gonadal steroid treatment (Fig. 4).

Although in general the rostro-caudal distribution of SOM-ir cells was comparable between different steroid treatment groups, the number of SOM-ir cells appeared to differ between steroid treatments in specific PeVN subregions. $\mathrm{E}_{2}$ or $\mathrm{P}$ treatment alone led to a decrease in the number of SOM-ir cells mainly in the anterior and medial parts of the PeVN compared to the untreated OVX females, whereas the combined treatment with $\mathrm{E}_{2}$ and $\mathrm{P}$ increased the number of SOM-ir cells particularly in the medial and posterior parts of the PeVN compared to OVX, even though not significantly (Fig. 4).

Effect of sex and gonadal steroids on SOM cells and SOM-ir area in the PeVN

Both the total number of SOM-ir cells and the SOM-ir area (i.e. above-threshold SOM peptide "presence") in the PeVN was significantly higher in males compared to all OVX female groups, irrespective of gonadal steroid treatment (Fig. 5a, b).

$\mathrm{E}_{2}$ or $\mathrm{P}$ treatment alone affected neither the total number of SOM-ir cells nor the total SOM-ir area in the PeVN (Fig. 5a, b). Treatment with both $\mathrm{E}_{2}$ and $\mathrm{P}$ increased the
SOM-ir area, but only significantly when compared to treatment with $\mathrm{P}$ alone (Fig. 5b). This effect of combined $\mathrm{E}_{2}$ and $\mathrm{P}$ on the number of SOM-ir cells and on the SOM-ir area was most pronounced in the medial and posterior parts of the PeVN, although the differences in each sub-region did not reach statistical significance (data not shown).

Effect of OVX length on SOM cells in the PeVN of $\mathrm{E}_{2}$-treated rats

The total number of SOM-ir cells in the PeVN was significantly lower in long-term (3 months) compared with shortterm ( 2 weeks) ovariectomized females after $\mathrm{E}_{2}$-treatment (Fig. 6; insert). This difference in SOM-ir cell number between long-term and short-term OVX was significant in the anterior and medial, but not in the caudal PeVN (Fig. 6).

In contrast, total SOM-ir area in the PeVN did not differ between long-term and short-term OVX (36,235 \pm $6,531 \mu \mathrm{m}^{2}$ for short-term and $23,207 \pm 3,582 \mu \mathrm{m}^{2}$ for longterm OVX, respectively), whereas OVX length significantly decreased SOM-ir area in the anterior PeVN $\left(5,628 \pm 810 \mu \mathrm{m}^{2}\right.$ for short-term and 2,467 $\pm 368 \mu \mathrm{m}^{2}$ for long-term OVX, respectively).

\section{Discussion}

The distribution of SOM cells within the male and female rat PeVN has not been described in great detail previously. Our study clearly shows a sex difference in the periventricular SOM-ir cell distribution. The rostro-caudal distribution being similar, both the relative total number of SOM-ir cells and the SOM-ir area differed markedly between the sexes, with males having significantly more SOM-ir cells and a higher SOM-ir area than OVX females. In addition, we show that in the female rat gonadal steroids modulate SOM peptide immunoreactivity in the PeVN, and that the number of SOM-ir cells is dependent on the period without gonadal steroid hormones (as a result of ovariectomy).

The higher number of SOM-ir neurons in males compared to females correlates with previous studies also 
Fig. 3 SOM cell distribution in the PeVN. Camera lucida drawings of immunoreactive somatostatin cells throughout the PeVN of the adult rat. Cell bodies at the left (female) and right (male) side of the third ventricle are indicated by open circles. These are drawings of the nine successive $\mathrm{PeVN}$ sections of one representative OVX $+\mathrm{E}_{2}$ and one representative male rat. $I I I$ third ventricle; o.c. optic chiasm; $S C N$ suprachiasmatic nucleus

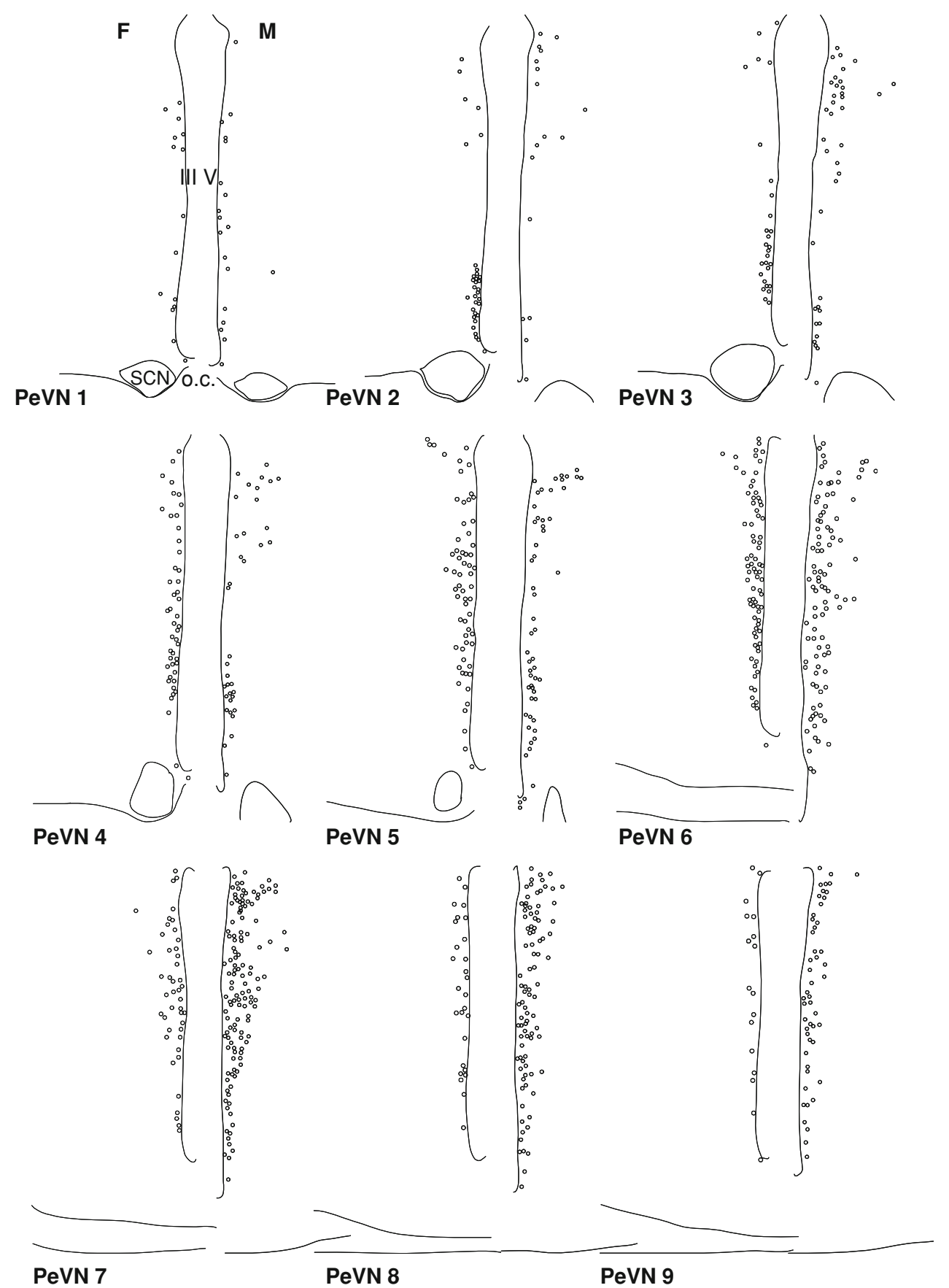

showing higher SOM mRNA levels (Chowen-Breed et al. 1989; Muller et al. 1999) and a higher SOM peptide content (Murray et al. 1999a, b; Nurhidayat et al. 2001) in the PeVN of male compared to female rats.

In our study $\mathrm{E}_{2}$ treatment in OVX (3 mo.) female rats did not have any effect on periventricular SOM-ir area, which is in line with Estupina et al. (1996) who also failed to observe effects of $\mathrm{E}_{2}$ on total hypothalamic SOM peptide content in OVX rats. However, several other studies showed that the effects of OVX on SOM mRNA levels in the PeVN could be reversed by $\mathrm{E}_{2}$ (Baldino et al. 1988;
Werner et al. 1988; Zorilla et al. 1990). These data strongly indicate that the effects of $\mathrm{E}_{2}$ on hypothalamic SOM cell activity are controversial and may be different with respect to synthesis, peptide storage and/or release.

The role of $\mathrm{P}$ in the regulation of hypothalamic SOM mRNA or peptide in the female rat has not been studied before, as far as we know. Studies using rat anterior pituitary cells show no effects of $\mathrm{P}$ on SOM-suppressed GH release (Fukata and Martin 1986), suggesting that P does not affect SOM receptor sensitivity or its expression on somatotrophs. In the present study we found that treatment with the 


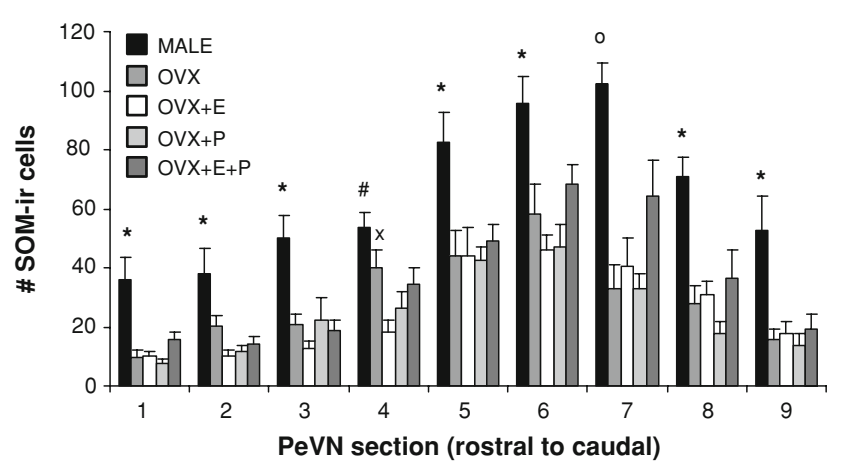

Fig. 4 Average number of SOM cells in the PeVN. Number of SOMir cells in the nine successive PeVN sections of male (black bars), OVX female (gray bars), OVX $+\mathrm{E}_{2}$ female (white bars), $\mathrm{OVX}+\mathrm{P}$ (light gray bars), and $\mathrm{OVX}+\mathrm{E}_{2}+\mathrm{P}$ female (dark gray bars) rats. Bars represent means \pm SEM. $N=8$ for each group. Overall testing revealed significant differences between male and female groups. Significant $(P<0.05)$ post hoc testing results for individual sections are indicated; males versus all female groups (asterisks) (PeVN sections 1-3, 5-6, 8-9), males versus OVX $+\mathrm{E}_{2}$ and OVX $+\mathrm{P}(\mathrm{PeVN}$ section 4) (Hash), males versus $\mathrm{OVX}, \mathrm{OVX}+\mathrm{E}_{2}$, and $\mathrm{OVX}+\mathrm{P}$ (PeVN section 7) (circle), OVX versus OVX $+\mathrm{E}_{2}(\mathrm{PeVN}$ section 4$)$ (cross)
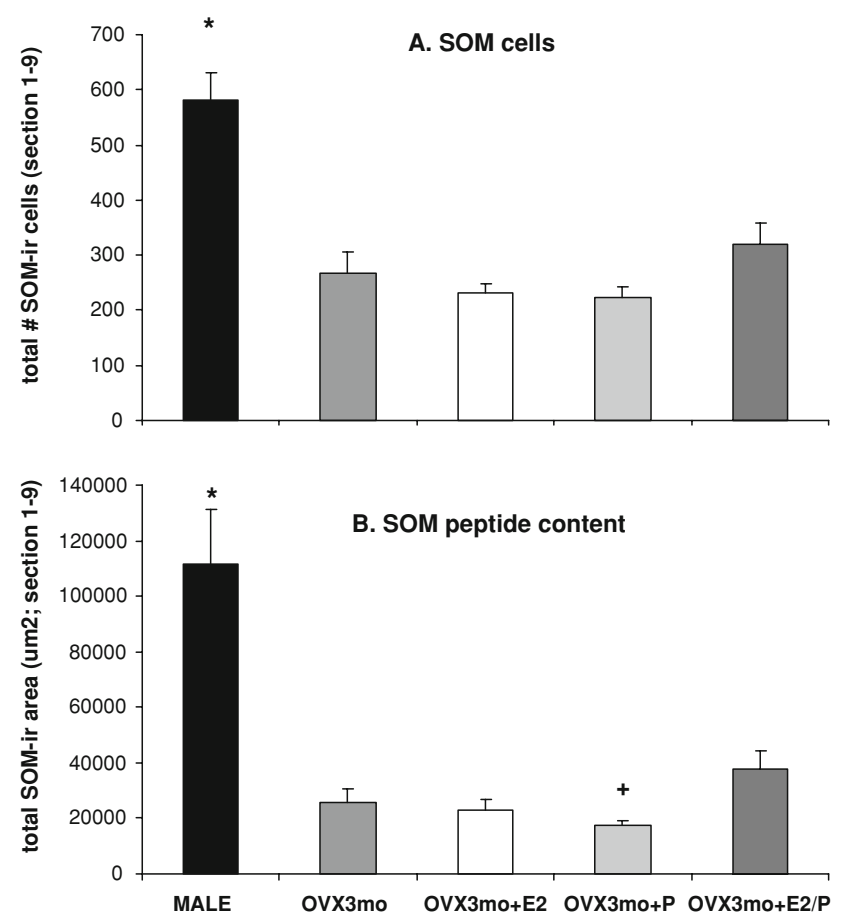

Fig. 5 Effect of gonadal steroids on SOM cells in the PeVN. Total (sections 1-9) number of SOM-ir cells (a) and total (sections 1-9) SOM-ir area (b; reflecting SOM peptide presence) in the PeVN of males and 3 months ovariectomized (OVX3mo) females with different gonadal steroid treatments. Bars represent means \pm SEM. Males versus all female groups (asterisk) $(P=0.000$; ANOVA); OVX $+\mathrm{P}$ versus $\mathrm{OVX}+\mathrm{E}_{2}+\mathrm{P}$ (plus) $(P=0.033$; Bonferroni)

combination of $\mathrm{E}_{2}$ and $\mathrm{P}$ slightly increased both the number of SOM-ir cells and the SOM-ir area in the PeVN compared to treatment with $\mathrm{E}_{2}$ (n.s.) or $\mathrm{P}(P<0.05)$ alone, indicating

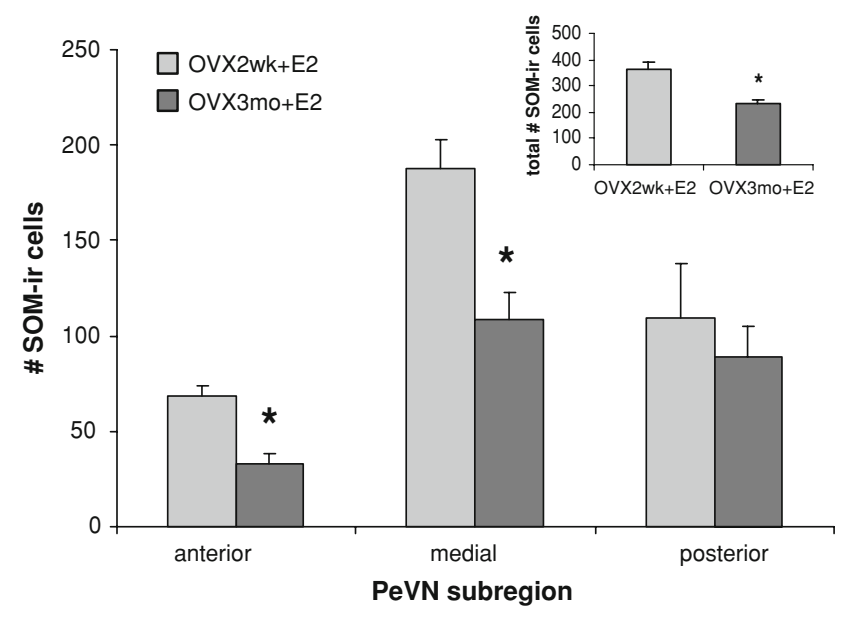

Fig. 6 Effect of OVX length on number of SOM cells. Total number of SOM-ir cells in each PeVN subregion of short-term ("OVX2wk + $\mathrm{E}_{2}$ "; light bars) and long-term ("OVX3mo + $\mathrm{E}_{2}$ "; dark bars) ovariectomized rats, treated with $\mathrm{E}_{2}$. Short-term versus long-term OVX females (asterisk) in the anterior ( $T$-test, $P=0.0004$ ) and medial ( $T$-test, $P=0.002$ ) PeVN. Insert: total (sections 1-9) number of SOMir cells in the PeVN was significantly higher in long-term compared with short-term $\mathrm{OVX}+\mathrm{E}_{2}$ rats. $T$-test, $P=0.001$ (asterisk)

that $\mathrm{P}$ may indeed modulate the activity of the hypothalamic SOM system in the female rat. This effect was most pronounced in the medial and posterior PeVN, suggesting that these parts of the PeVN may be more sensitive to gonadal steroids than the anterior part. These observations prompt and support the suggestion of specific subsets of SOM neurons within the $\mathrm{PeVN}$ with specific functions with regard to, for instance, the regulation of GH secretion (Argente et al. 1990; Epelbaum et al. 1986; Willoughby et al. 1989).

Although the precise role of gonadal steroids in the regulation of the activity of the periventricular SOM cells remains unclear, SOM synthesis in the hypothalamus and its release from the ME fluctuate during the estrous cycle: SOM mRNA in the PeVN was found to be minimal on the day of diestrus and maximal on the day of proestrus (Zorilla et al. 1991), when SOM peptide levels in the preoptic area, posterior hypothalamus and ME were shown to be low (Knuth et al. 1983). Yet, SOM release from the ME was found to be maximal on the day of proestrus (Estupina et al. 1996), concurrent with cyclic elevations of plasma $E_{2}$ and $P$ levels (Freeman 1994). These data suggest that $E_{2}$ or $P$, and more likely the combination of the two, affects SOM synthesis or release, or both, in the female rat. $\mathrm{E}_{2}$ and $\mathrm{P}$ may act synergistically to affect SOM peptide in the PeVN, and the combination of both gonadal hormones may thus be essential for the generation of the typical feminine hypothalamic SOM release pattern.

The effects of $E_{2}$ and $P$ on periventricular SOM cells are likely to be indirect. First, SOM neurons in the PeVN do not contain $\mathrm{E}_{2}$-receptors $\alpha(\mathrm{ER} \alpha)$ themselves (Herbison and Theodosis 1993; Kamegai et al. 2001; Scanlan et al. 2003), 
whereas $\mathrm{ER} \beta$ expression was not found in the $\mathrm{PeVN}$ at all (Kamegai et al. 2001; Simonian and Herbison 1997). $E_{2}$ may therefore indirectly affect SOM neurons in the PeVN via SOM cells located in nearby hypothalamic areas that contain ER $\alpha$ (Herbison 1994), or via GABA-containing neurons in the periventricular regions that have been shown to be $\mathrm{E}_{2}$-receptive (Flugge et al. 1986) and were found to project to SOM cells in the PeVN (Herbison and Augood 1994; Willoughby et al. 1987). Second, to our knowledge, no data exist on the presence of the progesterone-receptor (PR) in SOM cells in the hypothalamus. Although studies in the guinea pig show that SOM cells do contain PR (Dufourny and Warembourg 1996; Dufourny et al. 1998), no colocalization was found in the PeVN, suggesting that also the effect of $\mathrm{P}$ on SOM cells in the PeVN is likely to be indirect.

We found that the number of SOM-ir cells in the PeVN was also affected by the time following ovariectomy. Total SOM-ir cell numbers were significantly lower in long-term ( 3 months) compared to short-term (2 weeks) OVX females that were treated with $\mathrm{E}_{2}$. We did not include a short-term OVX group that was treated with vehicle for this study. However, in a previous study in our lab we found no effect of $E_{2}$ on the number of SOM-ir cells compared to vehicletreated animals after short-term OVX (unpublished results, 2001). These data suggest that the number of SOM-ir cells in the female PeVN is also dependent on OVX length rather than on $E_{2}$ treatment alone. Hence, also P may indeed play an essential role in the regulation of the periventricular SOM system in the female rat.

The effect of long-term OVX on SOM-ir cells was only significant in the anterior and medial parts of the PeVN, whereas the effects of gonadal steroids were most pronounced in the medial and posterior PeVN. These data again support the hypothesis for different subsets of SOM neurons within the PeVN with specific functions.

In conclusion, the present study indicates that SOM cell distribution, number of SOM cells, and SOM peptide content within the rat PeVN depend on gender and gonadal steroids. Moreover, our data suggest that in the female rat $\mathrm{E}_{2}$ and $\mathrm{P}$ act synergistically to affect SOM cell activity in the PeVN.

Acknowledgments The authors thank Mireille Baart (Wageningen University) for her help with the practical work.

Open Access This article is distributed under the terms of the Creative Commons Attribution Noncommercial License which permits any noncommercial use, distribution, and reproduction in any medium, provided the original author(s) and source are credited.

\section{References}

Argente J, Chowen-Breed JA, Steiner RA, Clifton DK (1990) Somatostatin messenger RNA in hypothalamic neurons is increased by testosterone through activation of androgen recep- tors and not by aromatization to estradiol. Neuroendocrinology 52:342-349

Baldino FJ, Fitzpatrick-McElligott S, O’Kane TM, Gozes I (1988) Hormonal regulation of somatostatin messenger RNA. Synapse 2:317-325

Bethea CL, Fahrenbach WH, Sprangers SA, Freesh F (1992) Immunocytochemical localization of progestin receptors in monkey hypothalamus: effect of estrogen and progestin. Endocrinology 130:895-905

Buijs RM, Pool CW, Van Heerikhuize JJ, Sluiter AA, Van der Sluis PJ, Ramkema M, Van der Woude TP, Van der Beek E (1989) Antibodies to small transmitter molecules and peptides: production and application of antibodies to dopamine, seretonin, GABA, vasopressin, vasoactive intestinal peptide, neuropeptide Y, somatostatin and substance P. Biomed Res 10:213-221

Chowen-Breed JA, Steiner RA, Clifton DK (1989) Sexual dimorphism and testosterone-dependent regulation of somatostatin gene expression in the periventricular nucleus of the rat brain. Endocrinology 125:357-362

Clark RG, Robinson IC (1985) Growth hormone responses to multiple injections of a fragment of human growth hormone-releasing factor in conscious male and female rats. J Endocrinol 106:281-289

Clark RG, Carlsson LM, Robinson IC (1987) Growth hormone secretory profiles in conscious female rats. J Endocrinol 114:399-407

Critchlow V, Abe K, Urman S, Vale W (1981) Effects of lesions in the periventricular nucleus of the preoptic-anterior hypothalamus on growth hormone and thyrotropin secretion and brain somatostatin. Brain Res 222:267-276

Dufourny L, Warembourg M (1996) Colocalization of progesterone receptor and somatostatin immunoreactivities in the hypothalamus of the male and female guinea pig. Neuroendocrinology 64:215-224

Dufourny L, Warembourg M, Jolivet A (1998) Multiple peptides infrequently coexist in progesterone receptor- containing neurons in the ventrolateral hypothalamic nucleus of the guinea-pig: an immunocytochemical triple-label analysis of somatostatin, neurotensin and substance P. J Neuroendocrinol 10:165-73

Eden S (1979) Age- and sex-related differences in episodic growth hormone secretion in the rat. Endocrinology 105:555-560

Epelbaum J, Tapia-Arancibia L, Alonso G, Astier H, Kordon C (1986) The anterior periventricular hypothalamus is the site of somatostatin inhibition of its own release: an in vitro and immunocytochemical study. Neuroendocrinology 44:255-259

Estupina C, Pinter A, Belmar J, Astier H, Arancibia S (1996) Variations in hypothalamic somatostatin release and content during the estrous cycle in the rat. Effects of ovariectomy and estrogen supplementation. Neuroendocrinology 63:181-187

Flugge G, Oertel WH, Wuttke W (1986) Evidence for estrogen-receptive GABAergic neurons in the preoptic/anterior hypothalamic area of the rat brain. Neuroendocrinology 43:1-5

Freeman ME (1994) The neuroendocrine control of the ovarian cycle of the rat. In: Knobil E, Neill JD (eds) The physiology of reproduction, vol 2. Raven Press, New York, pp 613-658

Fukata J, Martin JB (1986) Influence of sex steroid hormones on rat growth hormone-releasing factor and somatostatin in dispersed pituitary cells. Endocrinology 119:2256-2261

Gatford KL, Egan AR, Clarke IJ, Owens PC (1998) Sexual dimorphism of the somatotrophic axis. J Endocrinol 157:373-389

Gillies G (1997) Somatostatin: the neuroendocrine story. Trends Pharmacol Sci 18:87-95

Herbison AE (1994) Somatostatin-immunoreactive neurones in the hypothalamic ventromedial nucleus possess oestrogen receptors in the male and female rat. J Neuroendocrinol 6:323-328

Herbison AE, Augood SJ (1994) Expression of GABAA receptor alpha 2 sub-unit mRNA by periventricular somatostatin neurones in the rat hypothalamus. Neurosci Lett 173:9-13 
Herbison AE, Theodosis DT (1993) Absence of estrogen receptor immunoreactivity in somatostatin (SRIF) neurons of the periventricular nucleus but sexually dimorphic colocalization of estrogen receptor and SRIF immunoreactivities in neurons of the bed nucleus of the stria terminalis. Endocrinology 132:1707-1714

Ishikawa K, Taniguchi Y, Kurosumi K, Suzuki M, Shinoda M (1987) Immunohistochemical identification of somatostatin-containing neurons projecting to the median eminence of the rat. Endocrinology 121:94-97

Jansson JO, Frohman LA (1987a) Differential effects of neonatal and adult androgen exposure on the growth hormone secretory pattern in male rats. Endocrinology 120:1551-1557

Jansson JO, Frohman LA (1987b) Inhibitory effect of the ovaries on neonatal androgen imprinting of growth hormone secretion in female rats. Endocrinology 121:1417-1423

Jansson JO, Ekberg S, Isaksson OG, Eden S (1984) Influence of gonadal steroids on age- and sex-related secretory patterns of growth hormone in the rat. Endocrinology 114:1287-1294

Jansson JO, Eden S, Isaksson O (1985) Sexual dimorphism in the control of growth hormone secretion. Endocr Rev 6:128-150

Kamegai J, Tamura H, Shimizu T, Ishii S, Sugihara H, Wakabayashi I (2001) Estrogen receptor (ER) $\alpha$, but not $\operatorname{ER} \beta$, gene is expressed in growth hormone-releasing hormone neurons of the male rat hypothalamus. Endocrinology 142:538-543

Kasting NW, Martin JB, Arnold MA (1981) Pulsatile somatostatin release from the median eminence of the unanesthetized rat and its relationship to plasma growth hormone levels. Endocrinology 109:1739-1745

Katakami H, Downs TR, Frohman LA (1988) Inhibitory effect of hypothalamic medial preoptic area somatostatin on growth hormone-releasing factor in the rat. Endocrinology 123:1103-1109

Korbonits M, Grossman AB (2004) Ghrelin: update on a novel hormonal system. Eur J Endocrinol 151:S67-S70

Knuth UA, Sikand GS, Casanueva FF, Friesen HG (1983) Changes in somatostatin-like activity in discrete areas of the rat hypothalamus during different stages of proestrus and diestrus and their relation to serum gonadotropin, prolactin, and growth hormone levels. Endocrinology 112:1506-1511

Merchenthaler I, Setalo G, Csontos C, Petrusz P, Flerko B, NegroVilar A (1989) Combined retrograde tracing and immunocytochemical identification of luteinizing hormone-releasing hormoneand somatostatin-containing neurons projecting to the median eminence of the rat. Endocrinology 125:2812-2821

Muller EE, Locatelli V, Cocchi D (1999) Neuroendocrine control of growth hormone secretion. Physiol Rev 79:511-607

Murray HE, Simonian SX, Herbison AE, Gillies GE (1999a) Correlation of hypothalamic somatostatin mRNA expression and peptide content with secretion: sexual dimorphism and differential regulation by gonadal factors. J Neuroendocrinol 11:27-33

Murray HE, Simonian SX, Herbison AE, Gillies GE (1999b) Ontogeny and sexual differentiation of somatostatin biosynthesis and secretion in the hypothalamic periventricular-median eminence pathway. J Neuroendocrinol 11:35-42

Nurhidayat, Tsukamoto Y, Sasaki F (2001) Role of the gonads in sex differentiation of growth hormone- releasing hormone and somatostatin neurons in the mouse hypothalamus during postnatal development. Brain Res 890:154-161

Painson JC, Tannenbaum GS (1991) Sexual dimorphism of somatostatin and growth hormone-releasing factor signaling in the control of pulsatile growth hormone secretion in the rat. Endocrinology 128:2858-2866

Paxinos G, Watson C (1986) The rat brain in stereotactic coordinates, 2nd edn. Academic Press INC, San Diego
Plotsky PM, Vale W (1985) Patterns of growth hormone-releasing factor and somatostatin secretion into the hypophysial-portal circulation of the rat. Science 230:461-463

Praputpittaya C, Arita J, Kimura F (1987) Growth hormone secretion after hypothalamic periventricular lesions in the rat. Neuroendocrinology 46:104-109

Scanlan N, Dufourny L, Skinner DC (2003) Somatostatin-14 neurons in the ovine hypothalamus: colocalization with estrogen receptor $\alpha$ and somatostatin-28 (1-12) immunoreactivity, and activation on response to estradiol. Biol Reprod 69:1318-1324

Simonian SX, Herbison AE (1997) Differential expression of estrogen receptor $\alpha$ and $\beta$ immunoreactivity by oxytocin neurons of rat paraventricular nucleus. J Neuroendocrinol 9:803-806

Somogyi P, Takagi H (1982) A note on the use of picric acid-paraformaldehyde-glutaraldehyde fixative for correlated light and electron microscopic immunocytochemistry. Neuroscience 7:17791783

Tannenbaum GS, Ling N (1984) The interrelationship of growth hormone $(\mathrm{GH})$-releasing factor and somatostatin in generation of the ultradian rhythm of GH secretion. Endocrinology 115:1952-1957

Tannenbaum GS, Painson JC, Lapointe M, Gurd W, McCarthy GF (1990) Interplay of somatostatin and growth hormone-releasing hormone in genesis of episodic growth hormone secretion. Metabolism 39:35-39

Tannenbaum GS, Farhadi-Jou F, Beaudet A (1993) Ultradian oscillation in somatostatin binding in the arcuate nucleus of adult male rats. Endocrinology 133:1029-1034

Terry LC, Martin JB (1981) The effects of lateral hypothalamic-medial forebrain stimulation and somatostatin antiserum on pulsatile growth hormone secretion in freely behaving rats: evidence for a dual regulatory mechanism. Endocrinology 109:622-627

Urman S, Kaler L, Critchlow V (1985) Effects of hypothalamic periventricular lesions on pulsatile growth hormone secretion. Neuroendocrinology 41:357-362

Van der Beek EM, Van Oudheusden HJ, Buijs RM, Van der Donk HA, Van den Hurk R, Wiegant VM (1994) Preferential induction of cfos immunoreactivity in vasoactive intestinal polypeptide-innervated gonadotropin-releasing hormone neurons during a steroidinduced luteinizing hormone surge in the female rat. Endocrinology 134:2636-2644

Werner H, Koch Y, Baldino F Jr, Gozes I (1988) Steroid regulation of somatostatin mRNA in the rat hypothalamus. J Biol Chem 263:7666-7671

Willoughby JO, Beroukas D, Blessing WW (1987) Ultrastructural evidence for gamma aminobutyric acid- immunoreactive synapses on somatostatin-immunoreactive perikarya in the periventricular anterior hypothalamus. Neuroendocrinology 46:268-272

Willoughby JO, Brogan M, Kapoor R (1989) Intrahypothalamic actions of somatostatin and growth hormone releasing factor on growth hormone secretion. Neuroendocrinology 50:592-596

Zeitler P, Tannenbaum GS, Clifton DK, Steiner RA (1991) Ultradian oscillations in somatostatin and growth hormone- releasing hormone mRNAs in the brains of adult male rats. Proc Natl Acad Sci USA 88:8920-8924

Zorilla R, Simard J, Rheaume E, Labrie F, Pelletier G (1990) Multihormonal control of pre-pro-somatostatin mRNA levels in the periventricular nucleus of the male and female rat hypothalamus. Neuroendocrinology 52:527-536

Zorilla R, Simard J, Labrie F, Pelletier G (1991) Variations of preprosomatostatin mRNA levels in the hypothalamic periventricular nucleus during the rat estrous cycle. Mol Cell Neurosci 2:294-298 